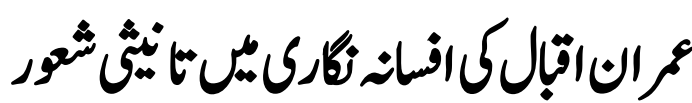

\section{Feminine Consciousness in Imran Iqbal's Fiction Writing}

$\underline{\text { Saira Irshad }}$

Lecturer, Urdu Department, Government Sadiq College Women University, Bahawalpur, Pakistan.

Madiha Naeem

Research Scholar, Urdu Department, Govertment Sadiq College Women University, Bahawalpur, Pakistan.

\section{KEYWORDS}

Feminine Consciousness

Economic Situation

Self-esteem

Humour

Mental Harrasement

Sexual Violence

Psychological Issues

Social Injustice

DATES

\begin{tabular}{ll}
\hline Received & $20-10-2021$ \\
Accepted & $09-12-2021$ \\
Published & $21-12-2021$ \\
QR CODE & \\
\hline
\end{tabular}

\section{ABSTRACT}

Imran Iqbal's name is prominent in Urdu fiction. He is from Bahawalpur but he is residing in the United States for employment. Imran Iqbal tried his hand at travelogues, fiction, novels and memoirs. He has made women and her issues the subject of his fictions. Imran Iqbal has presented a true picture of a woman who at every step faces various forms of male repressive behavior, outdated customs, husband and father-in-law atrocities, domestic violence and sexual harassment. Her fiction depicts women's psychological problems, the sexual appetites of landlords, capitalists, bureaucrats and top officials. Imran Iqbal has awakened Tanila consciousness through his pen.

DOI: https://doi.org/10.54064/negotiations.v1i3.25

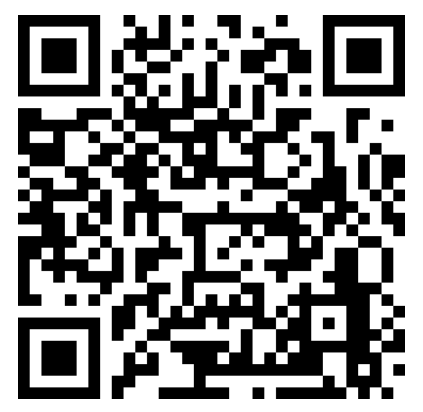

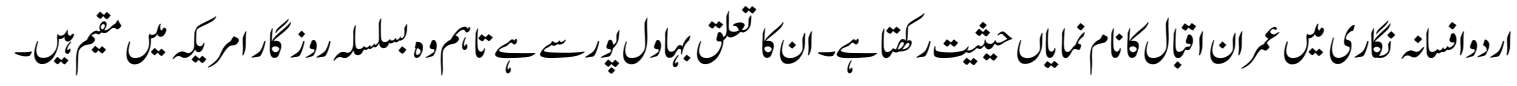

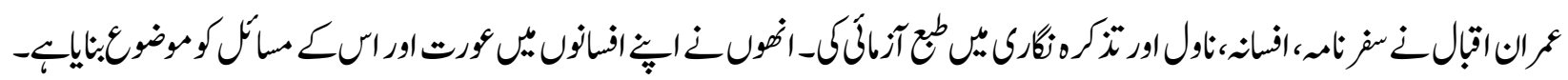

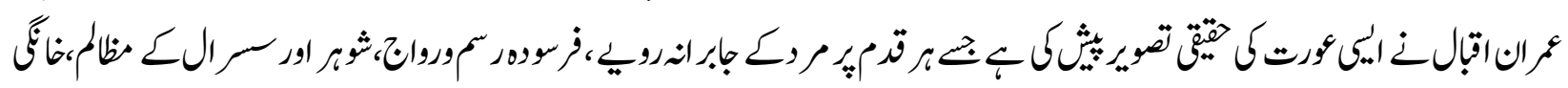

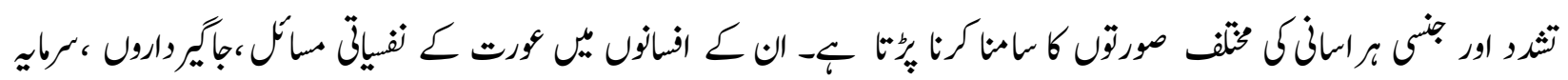

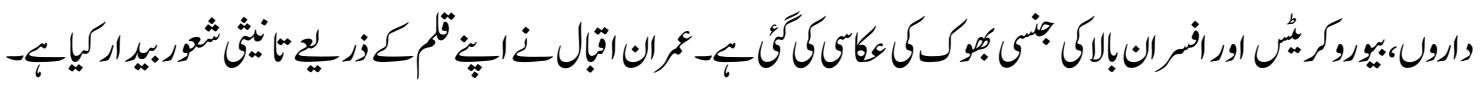




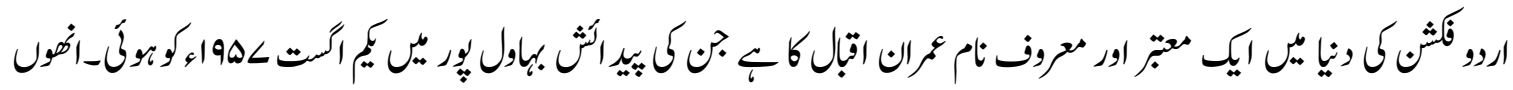

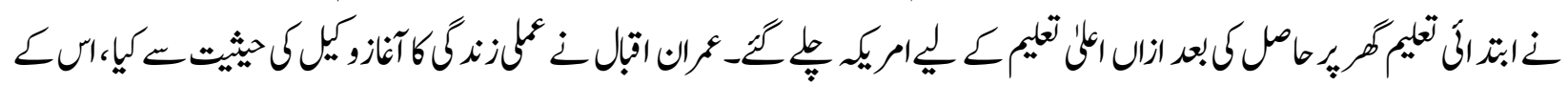

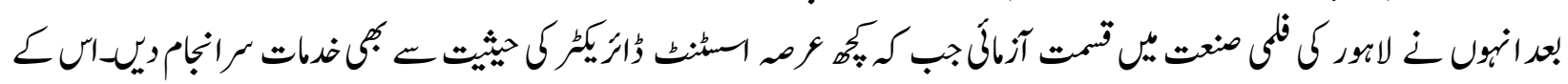

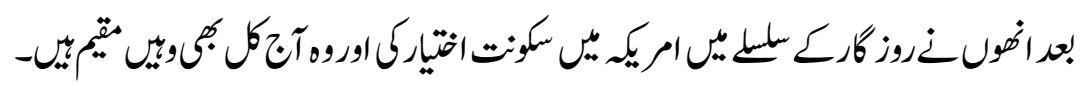

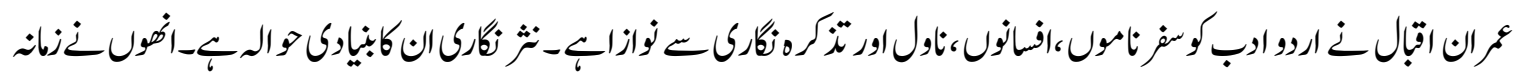

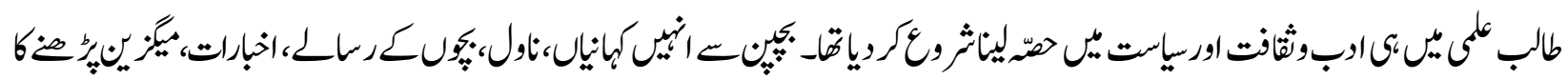

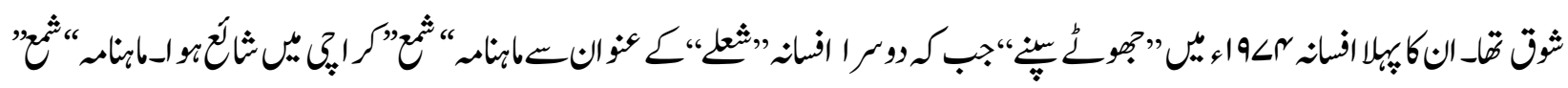

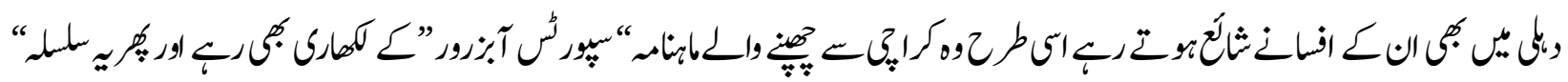

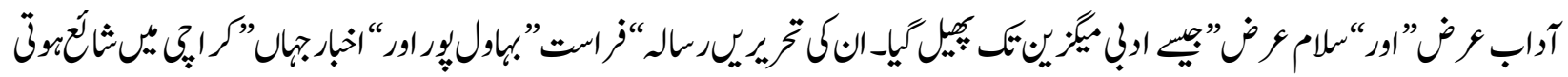

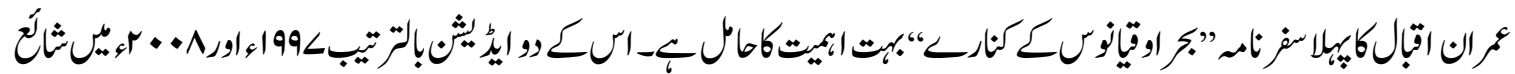

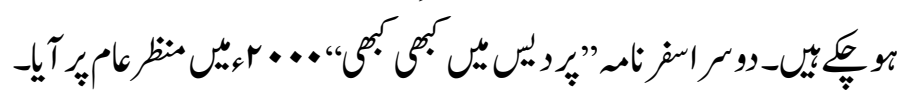

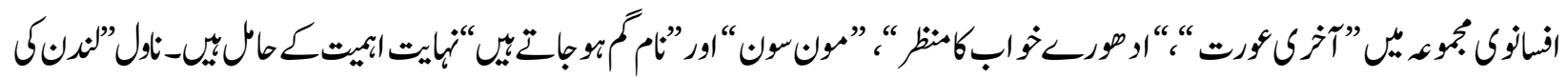

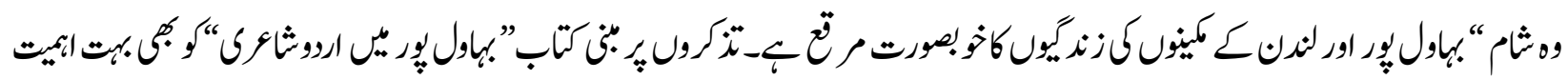

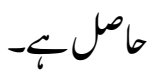

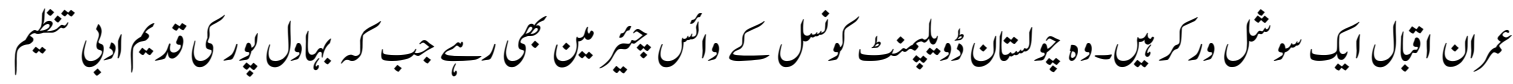

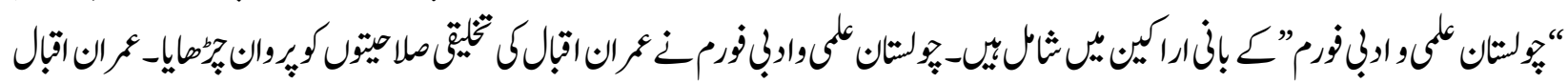

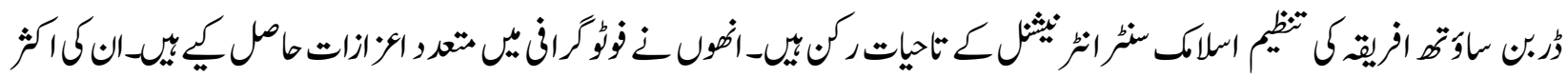

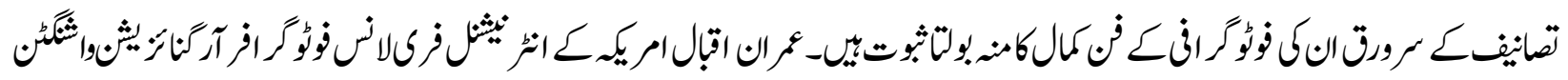

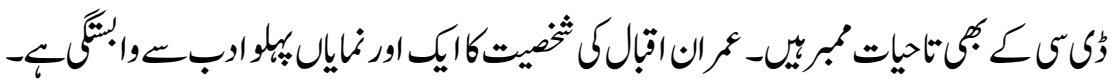

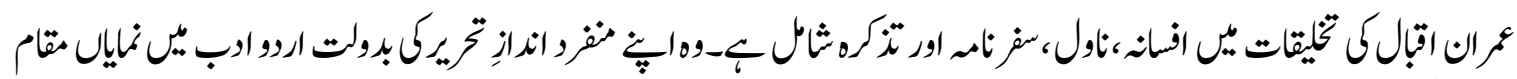

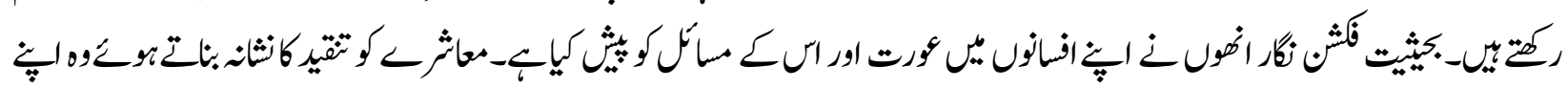

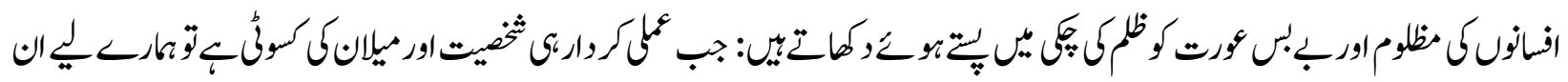

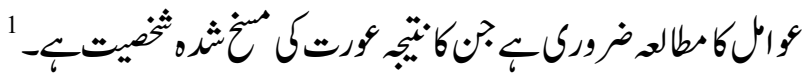




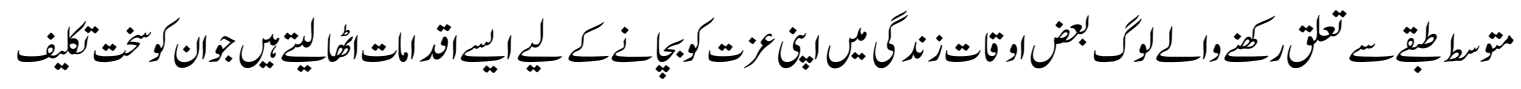

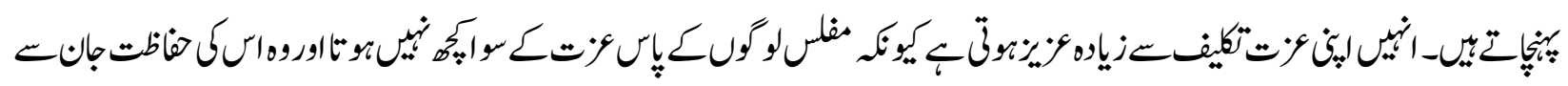

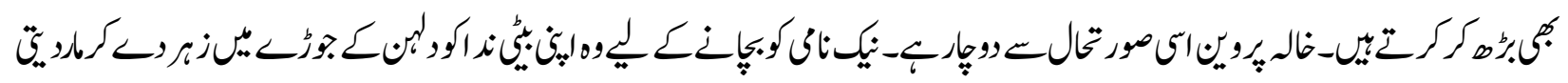

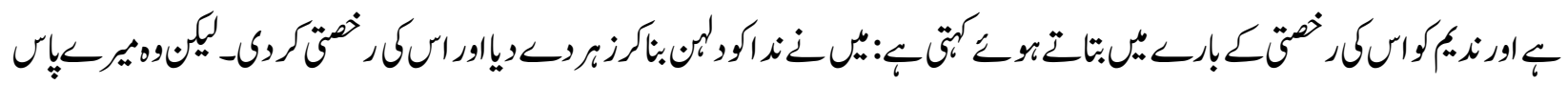

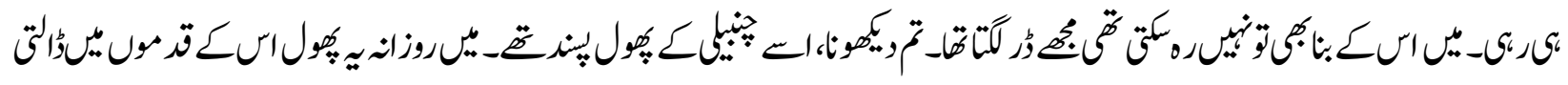
2

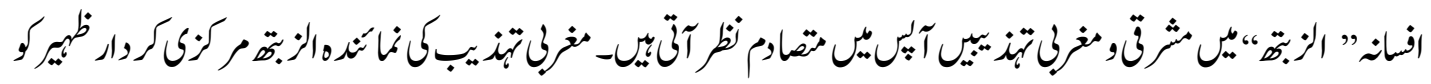

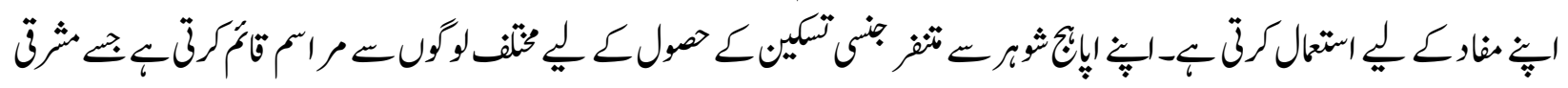

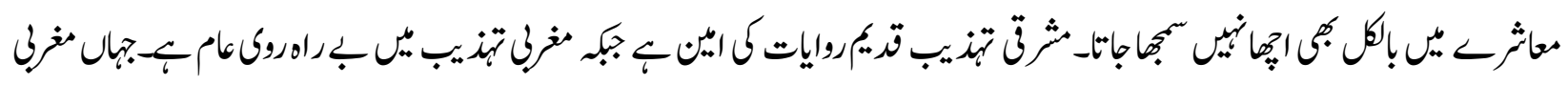

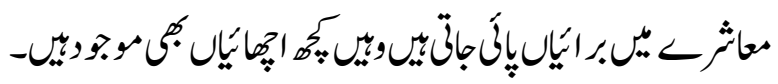

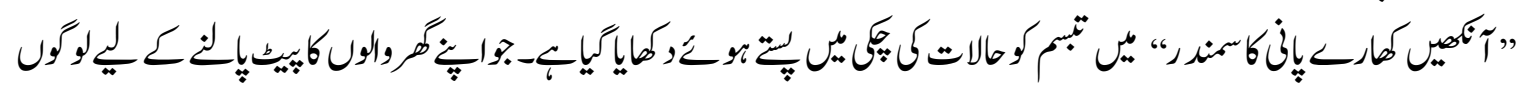

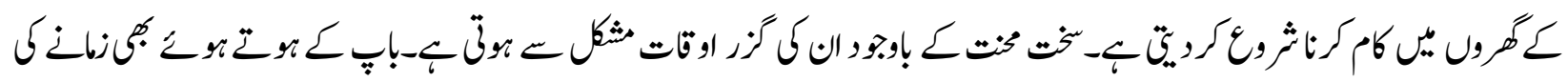

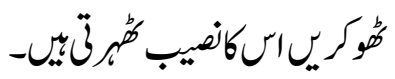

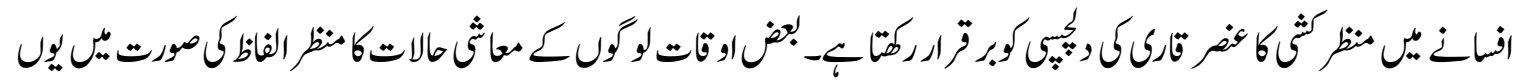

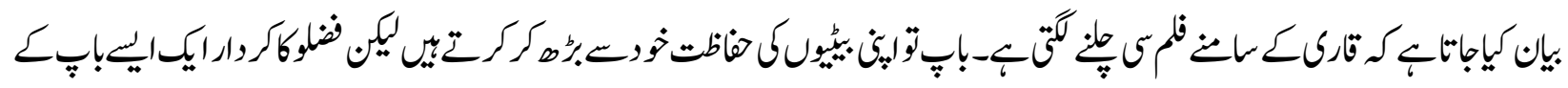

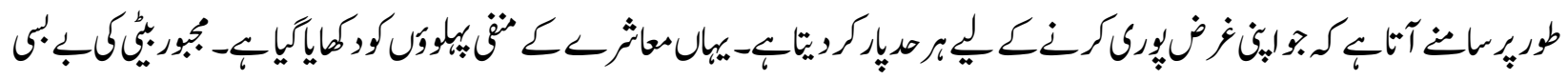

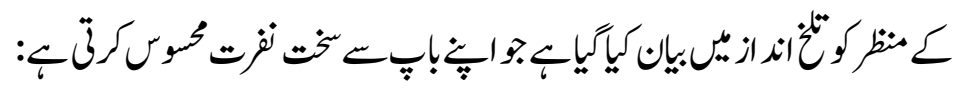

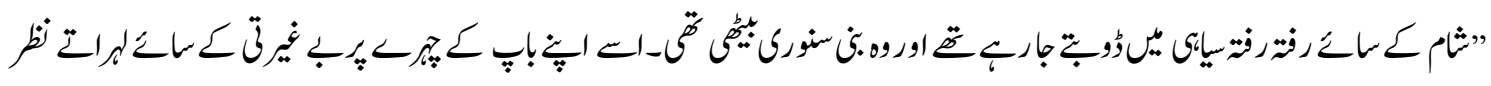

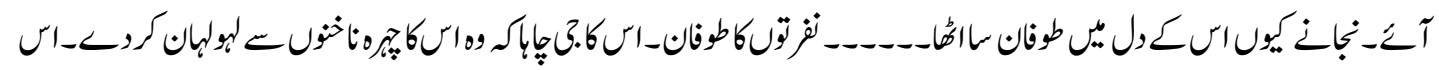

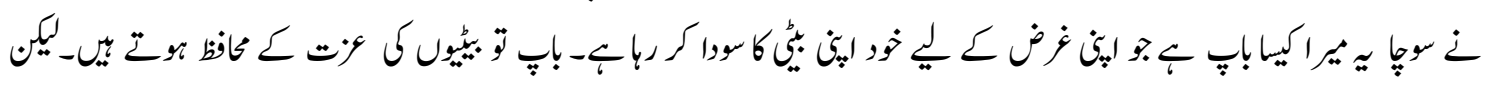

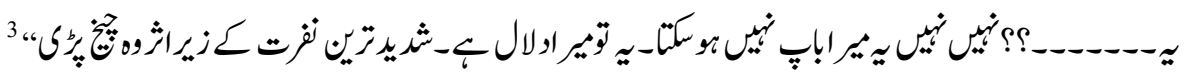

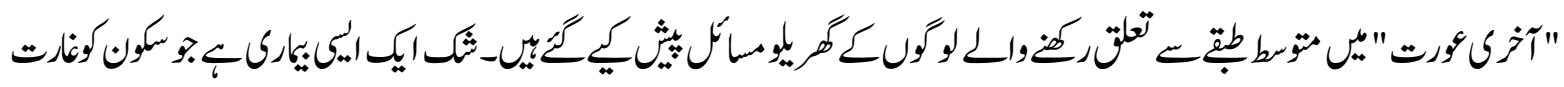

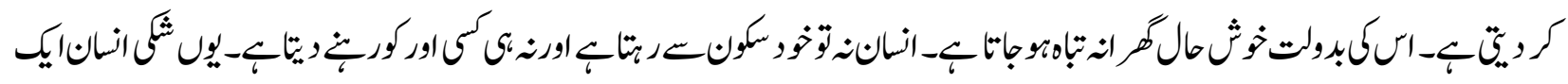

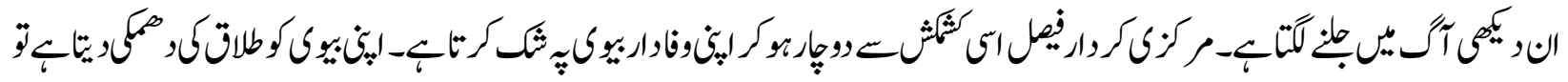

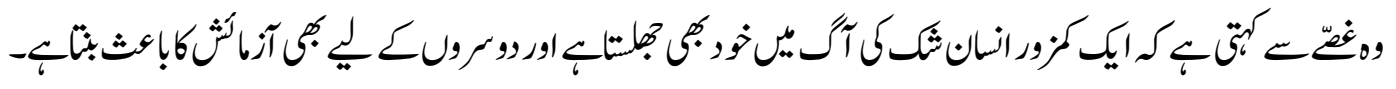




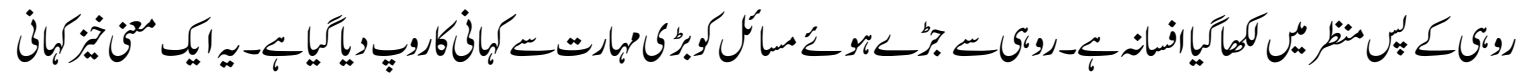

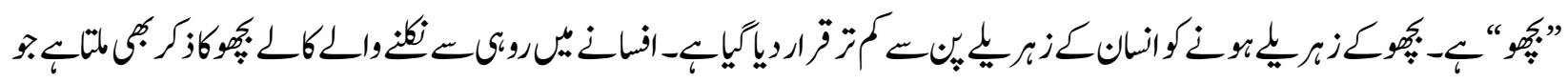

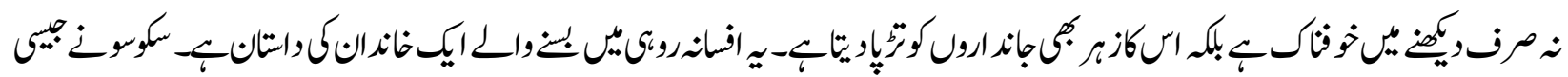

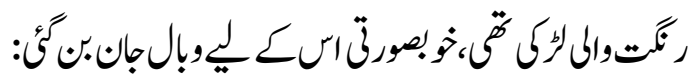

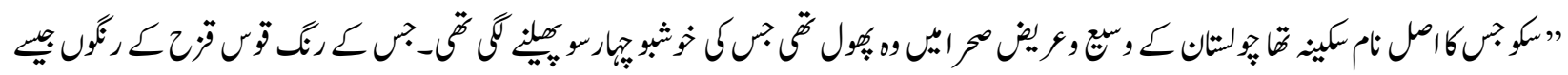

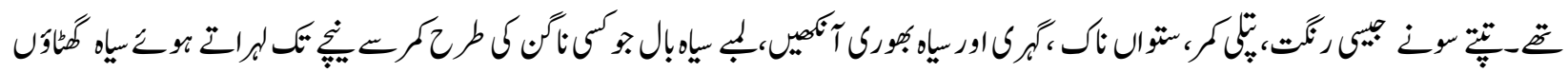

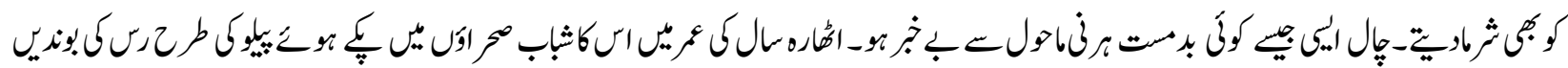

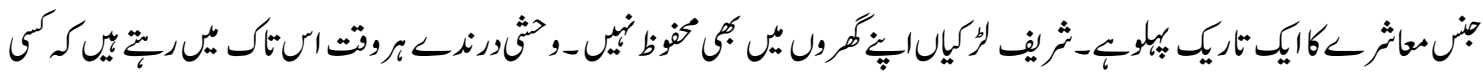

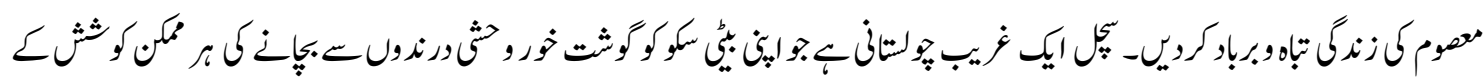

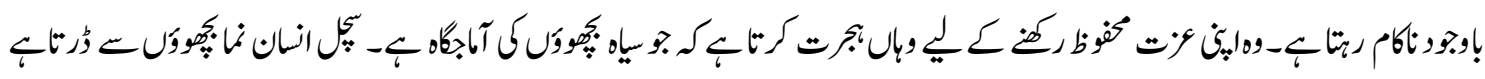

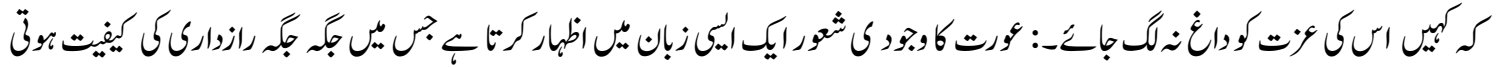

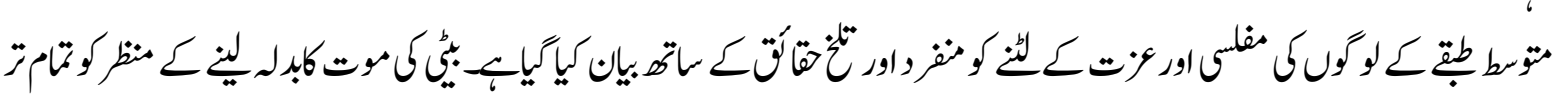

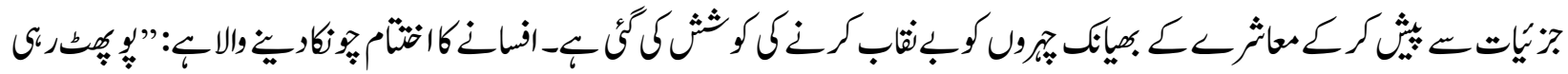

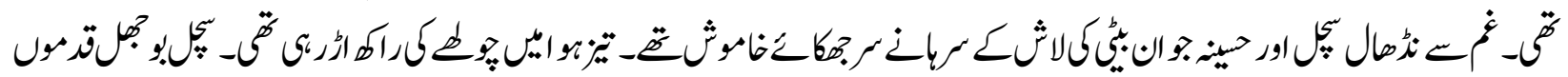

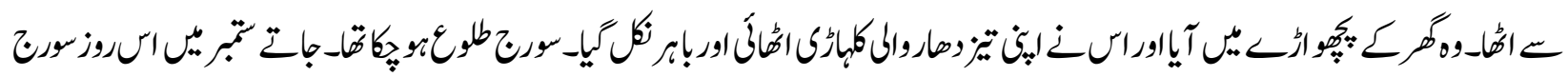

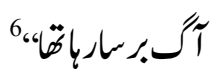

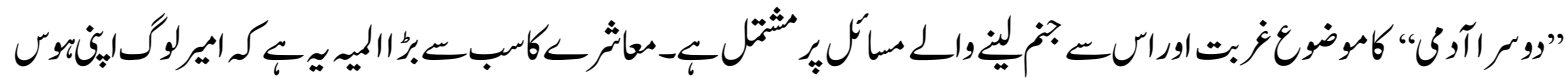

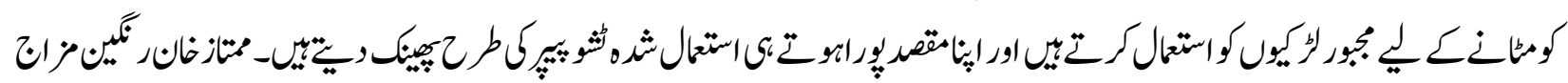

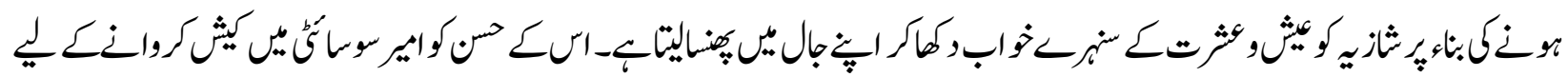

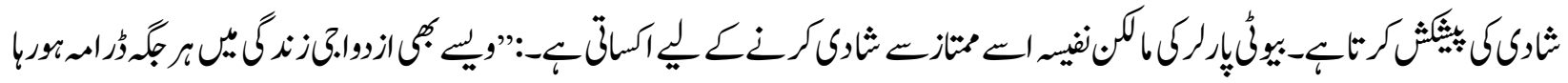

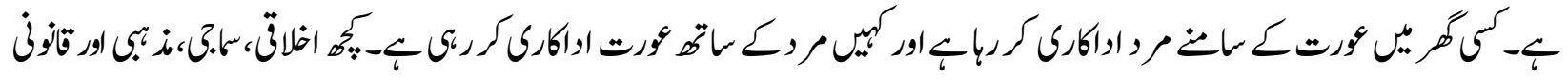

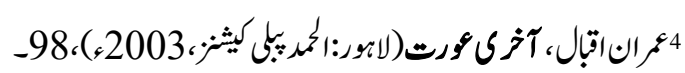

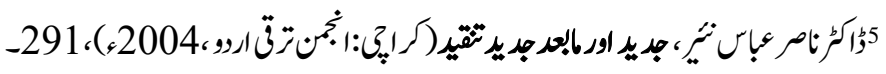

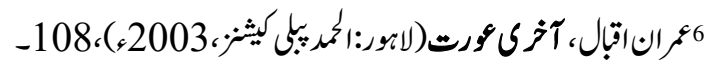




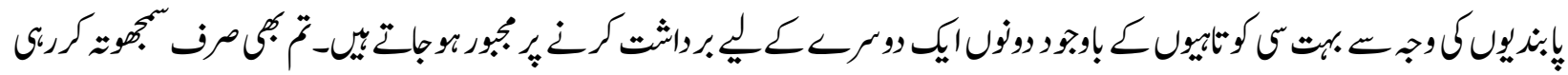

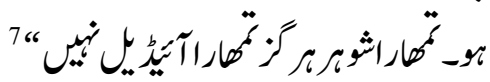

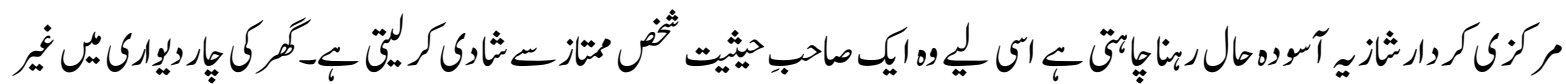

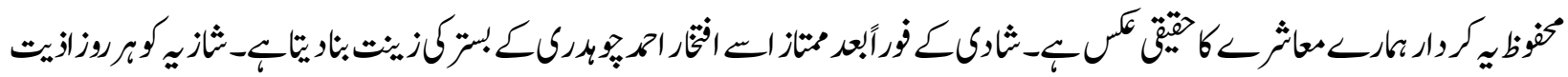

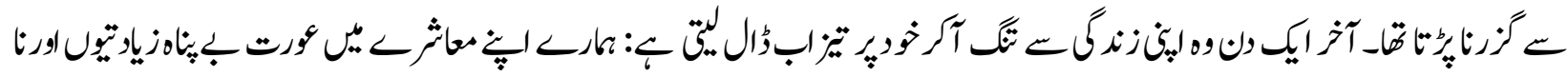

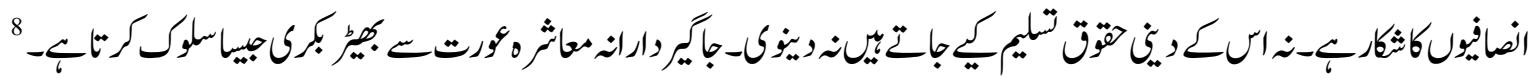

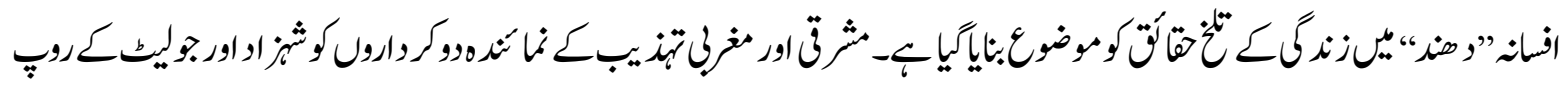

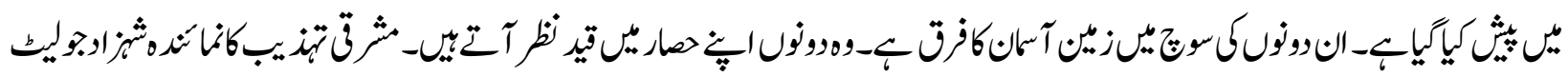

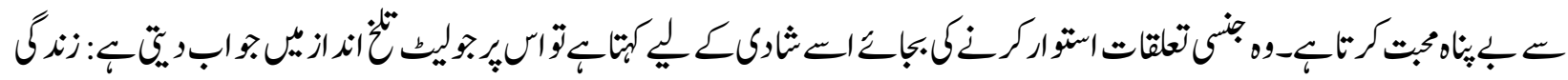

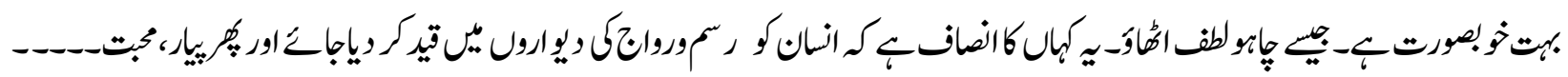

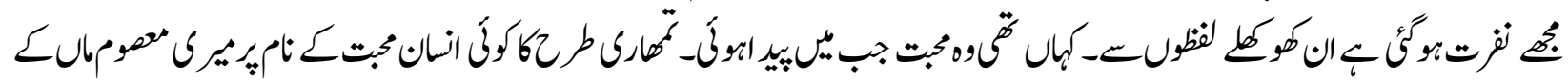

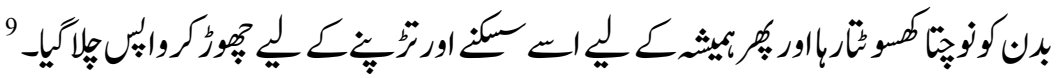

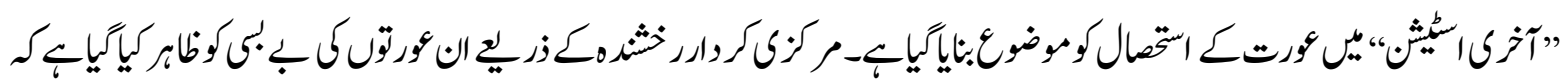

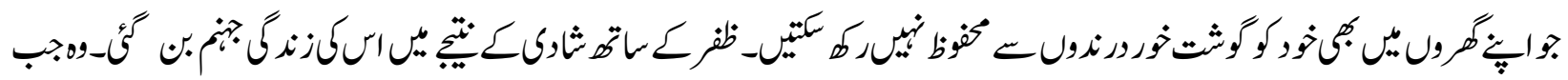

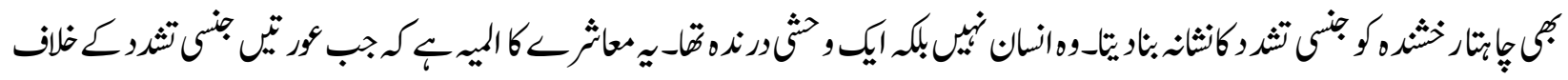

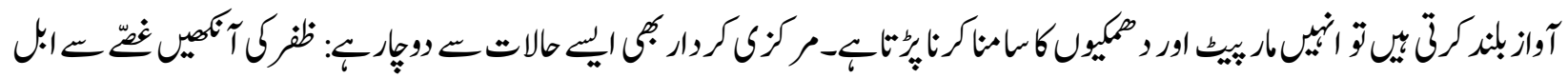

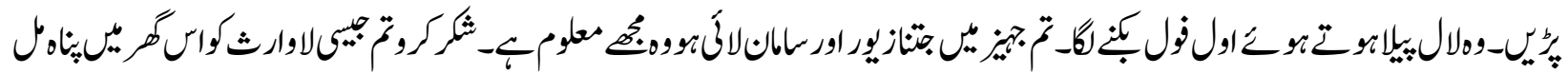

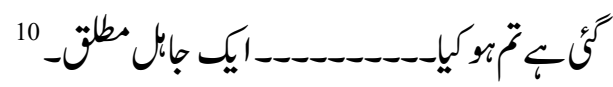

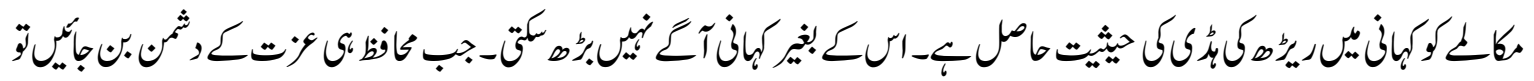

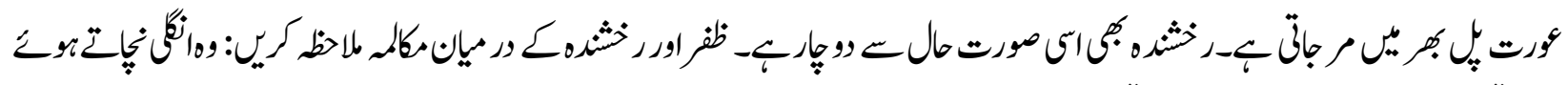

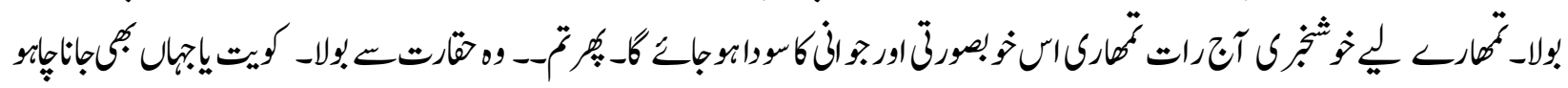

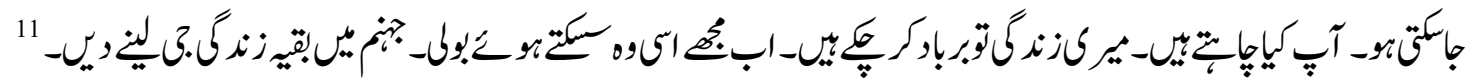

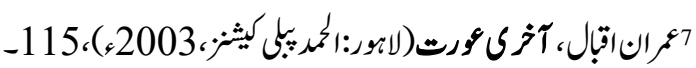

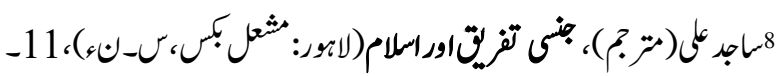

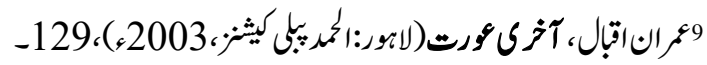

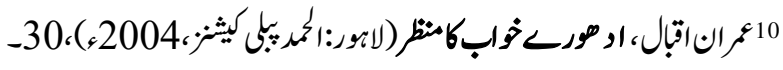

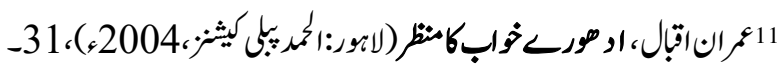




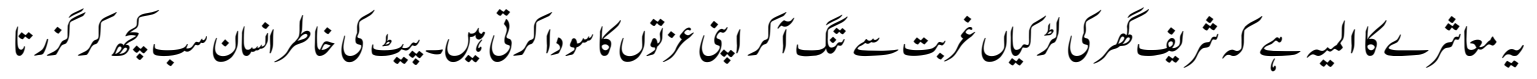

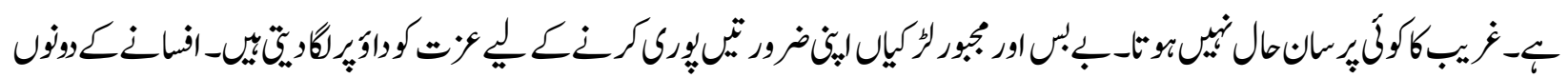

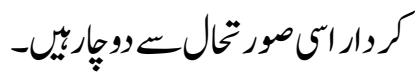

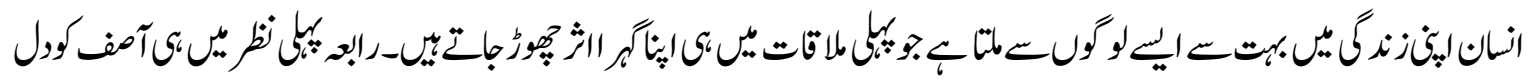

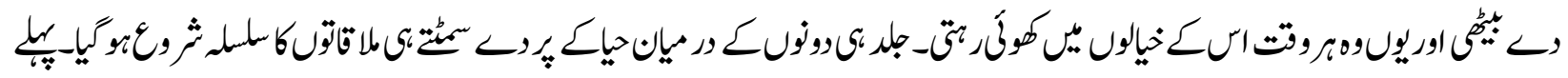

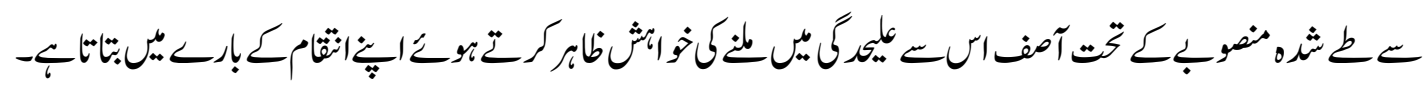

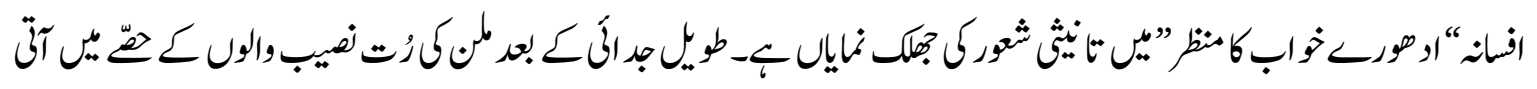

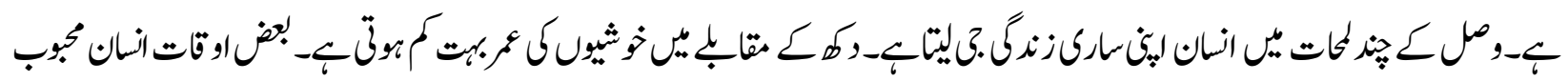

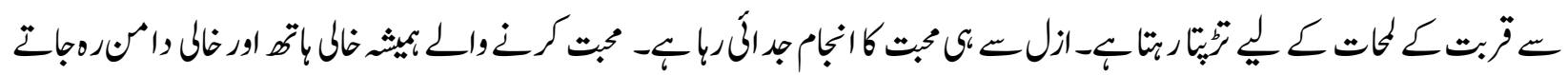

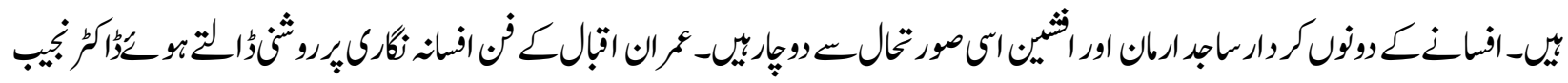

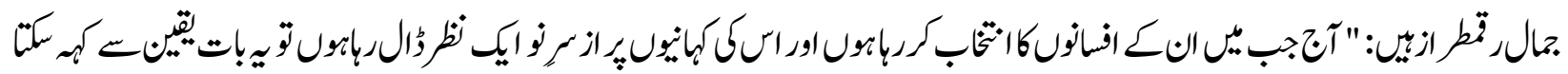

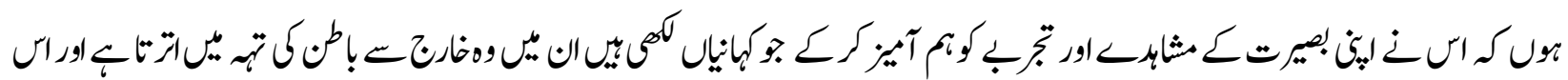

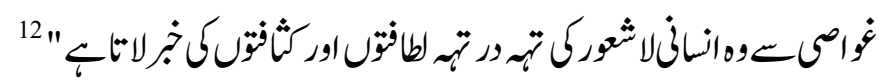

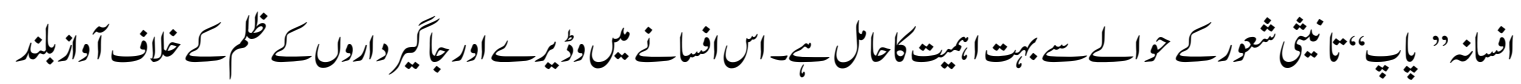

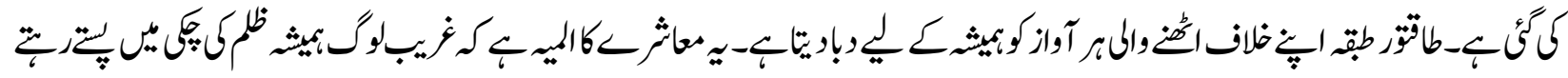

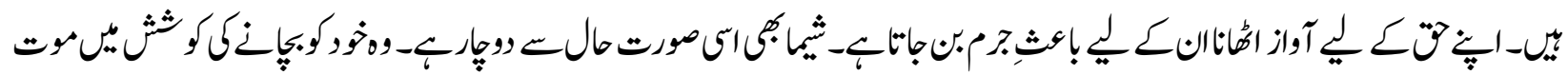

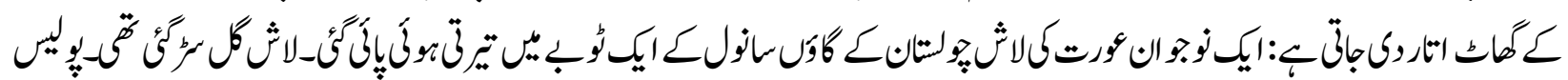

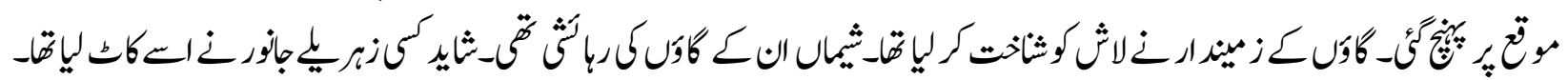

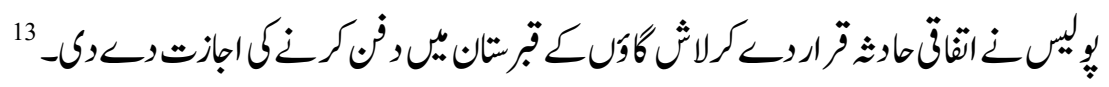

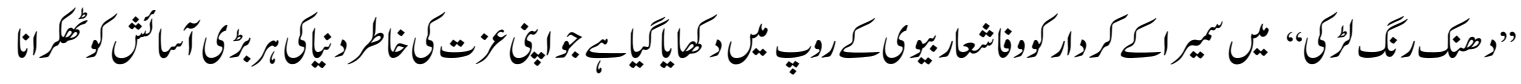

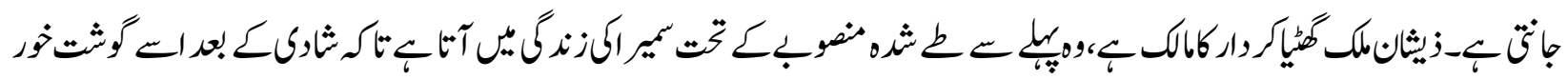

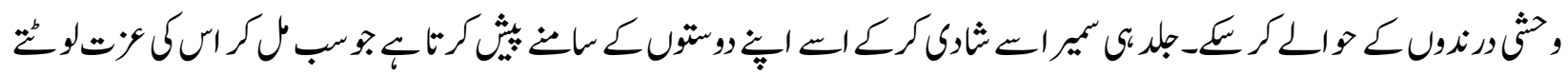




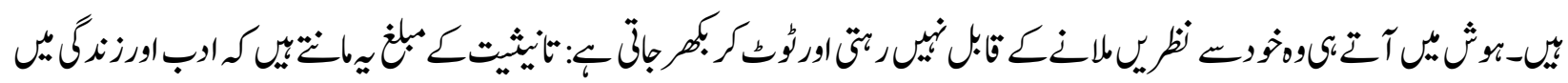

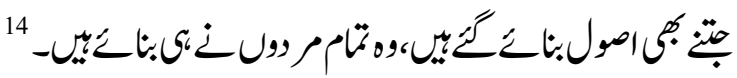

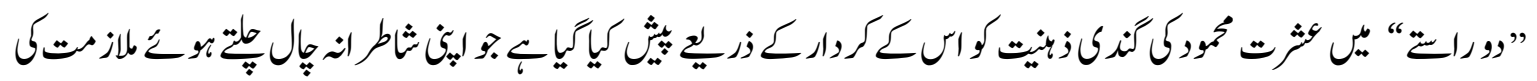

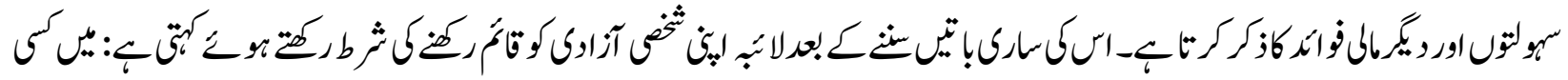

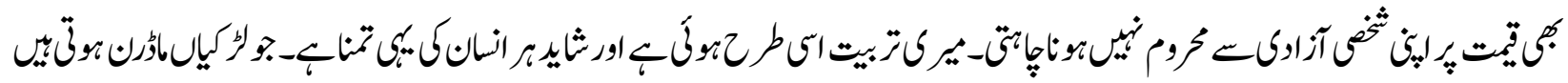

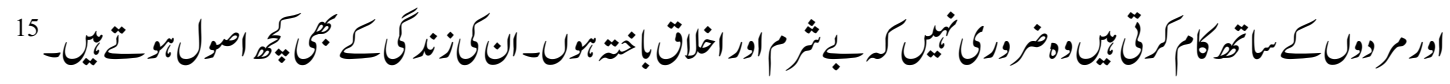

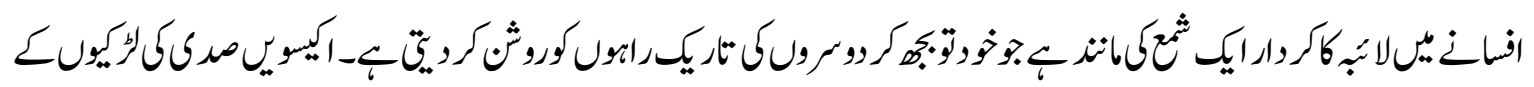

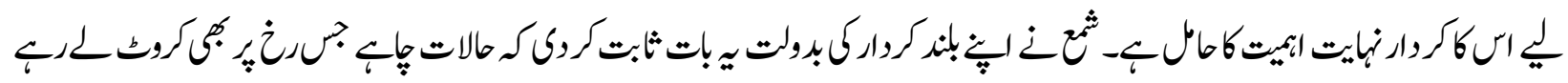

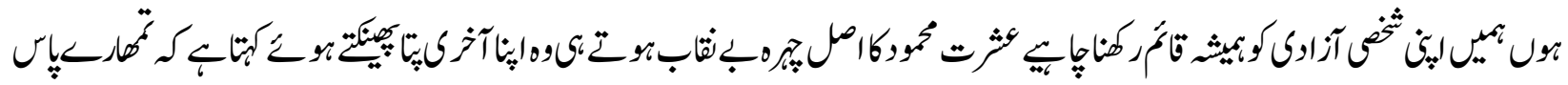

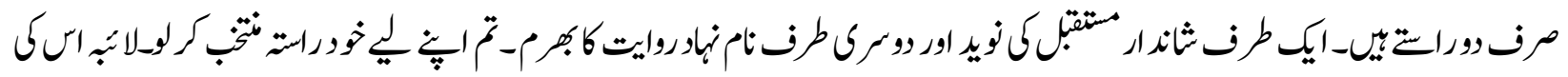

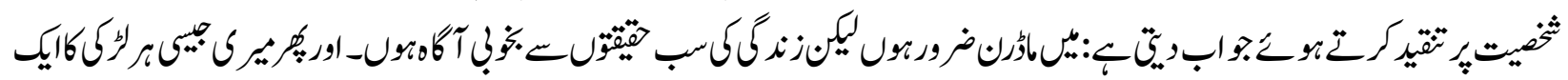

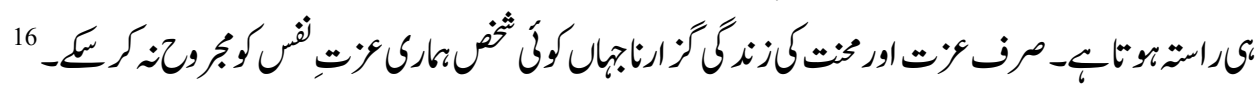

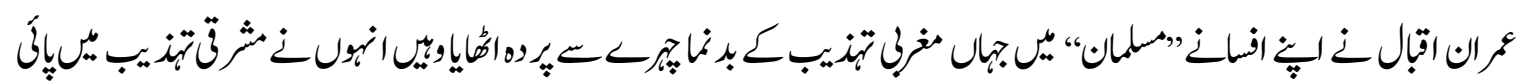

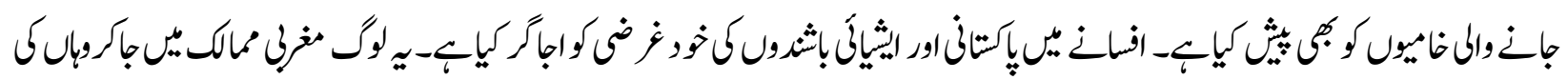

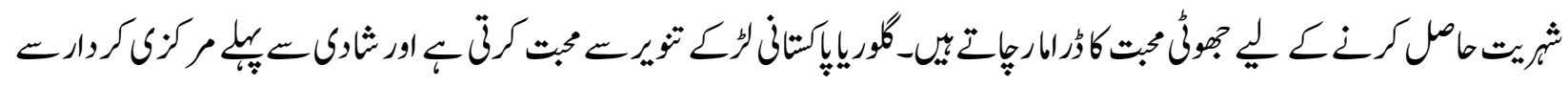

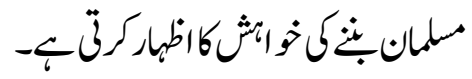

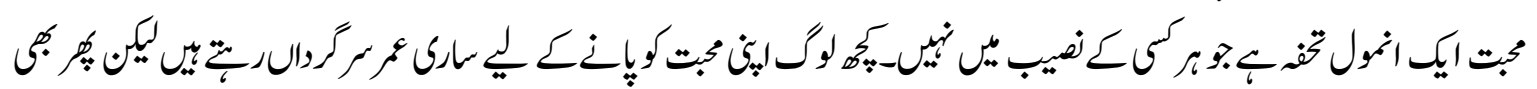

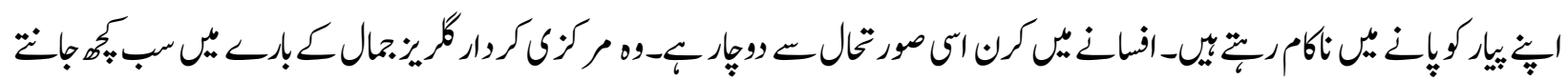

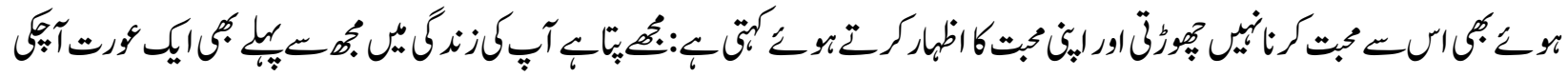

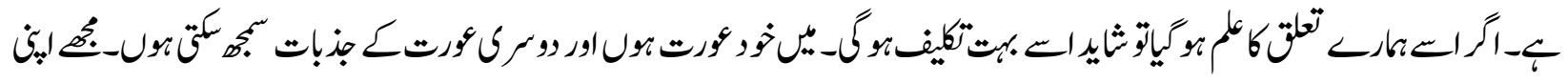

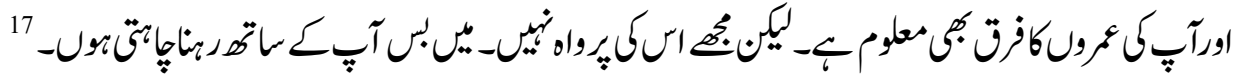

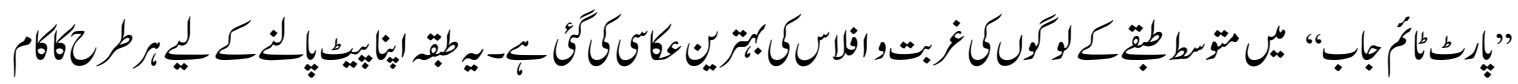

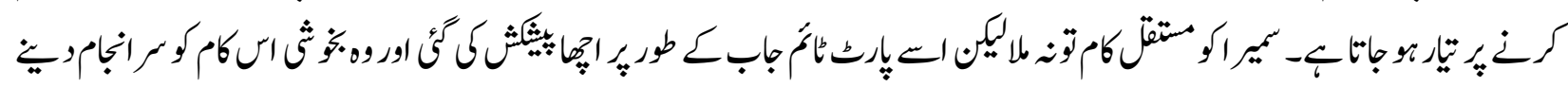

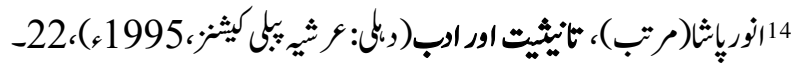

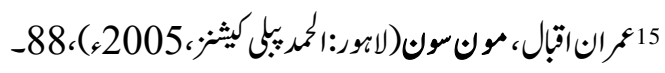
16 ايضا،90-

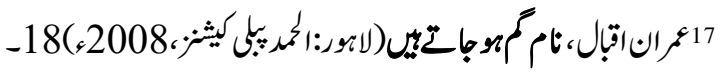




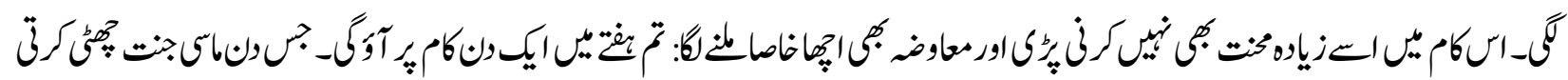

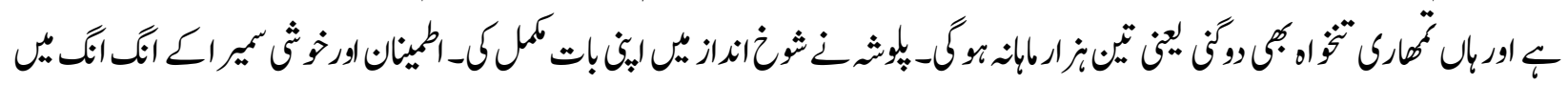

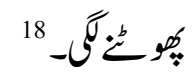

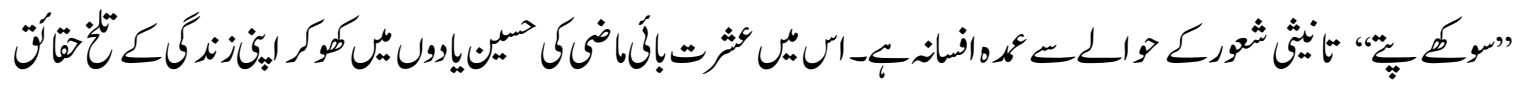

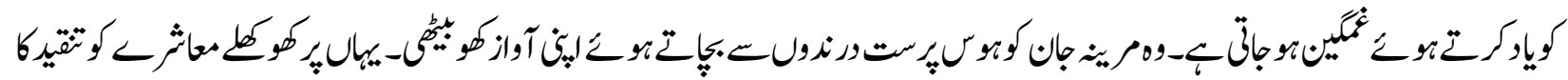

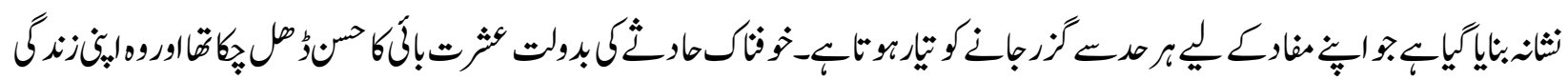

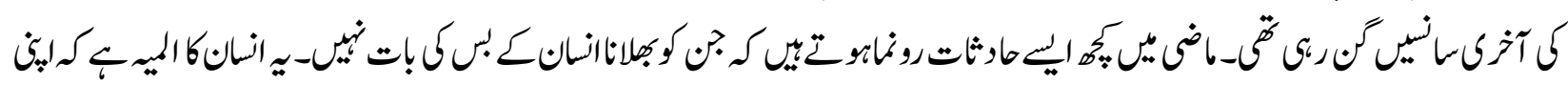

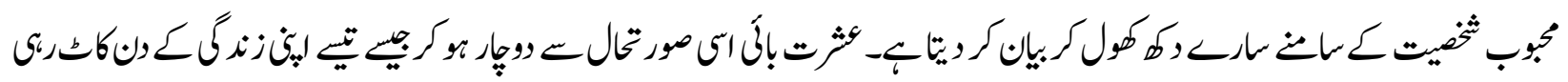

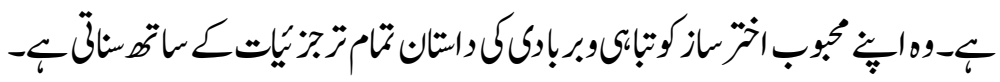

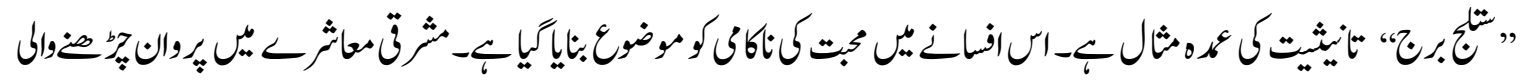

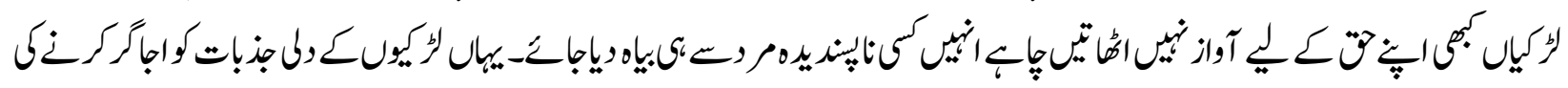

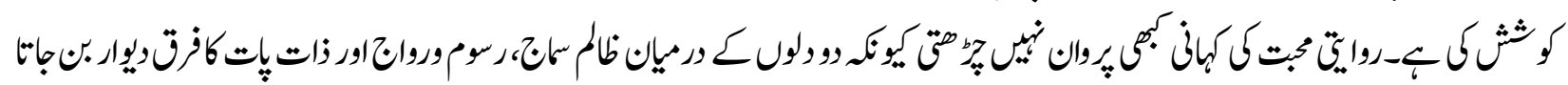

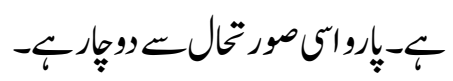

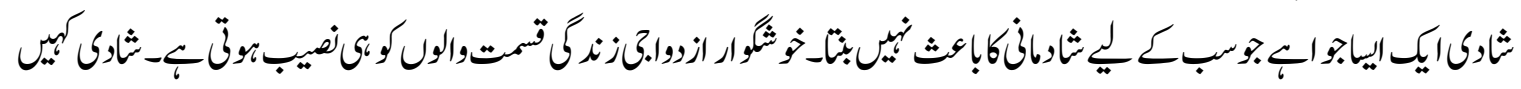

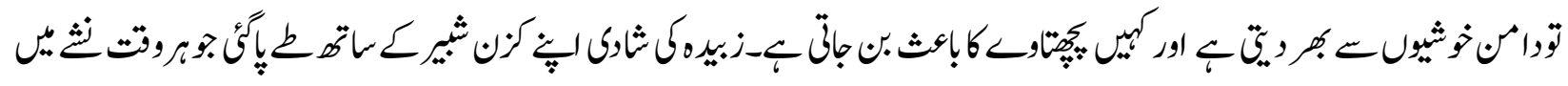

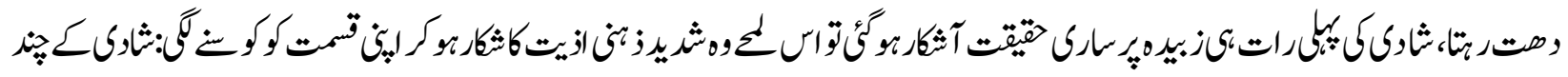

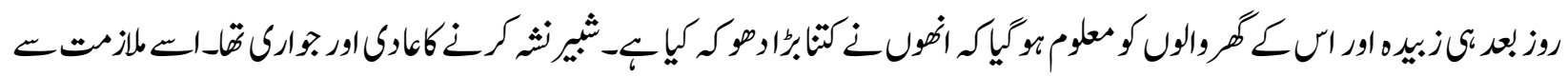

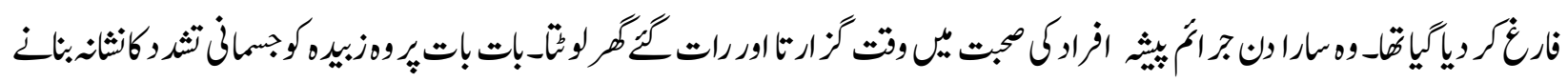

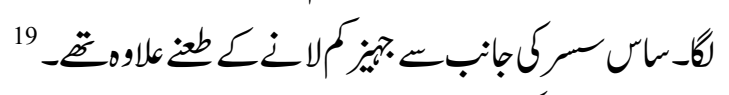

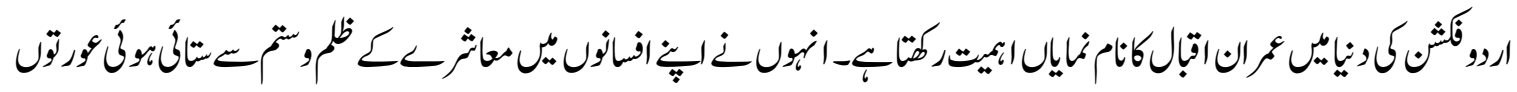

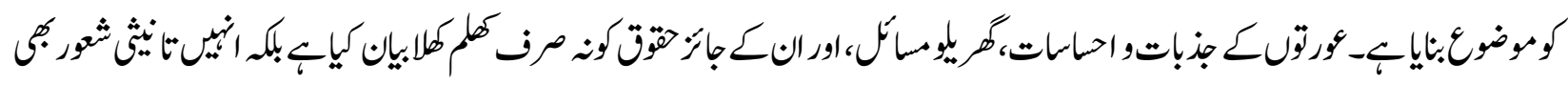

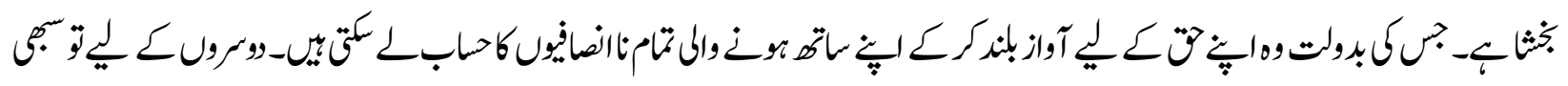

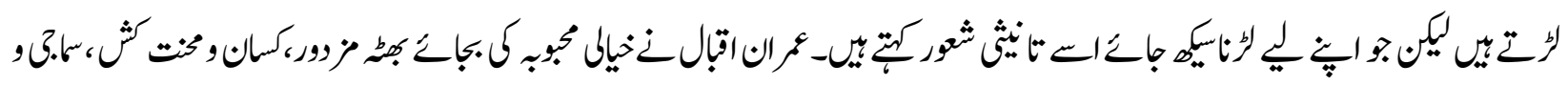

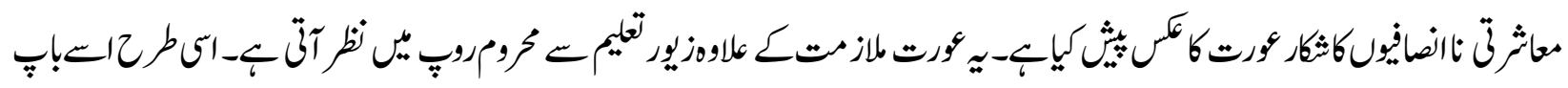




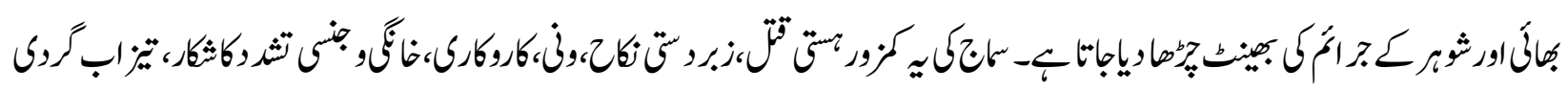

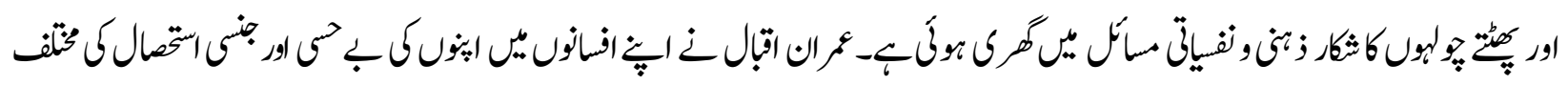

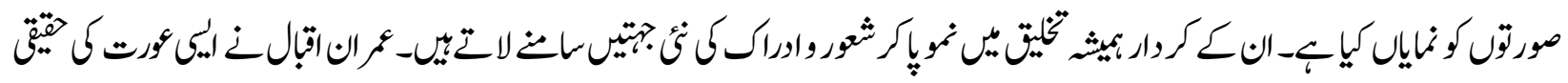

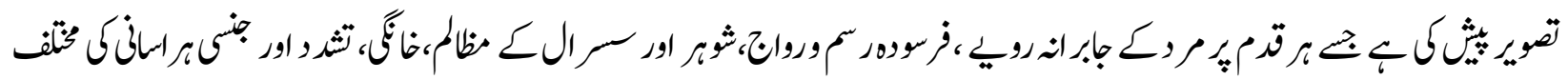

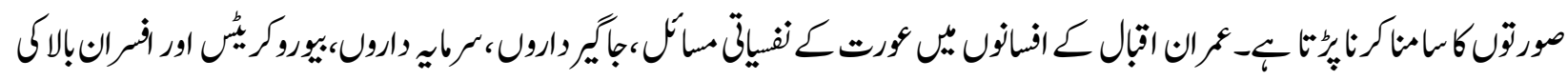

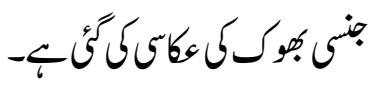

论败猔 